\title{
Çekme Yükü Altında Gömülü Tek Tesirli Yama ile Yapıştırılarak Birleştirilmiş Kompozit Parçaların Gerilme Analizi
}

\author{
İsmail Yasin SÜLÜ*
}

\author{
Inönü Üniversite, Makine Mühendisliği Bölümü, Malatya
}

\begin{abstract}
$\ddot{O} \mathbf{z}$
$\mathrm{Bu}$ çalışmada, çekme yüküne maruz bırakılmış gömülü tek tesirli yama ile yapıştırılarak birleştirilmiş kompozit parçaların üç boyutlu sonlu elemanlar yöntemi kullanılarak gerilme analizleri yapılmıştır. Analizlerde, farklı oryantasyon açılı karbon/epoksi (AS4/3501-6) kullanılarak üretilmiş kompozit parçalar ve DP410 tür yapıştıııcı kullanılmıştır. Nümerik analizler için modeller sonlu elemanlar yöntemine temellendirilmiş ANSYS paket programı kullanılarak oluşturulmuştur. Hasar yükleri analizler sonuçlarına göre tespit edilmiştir. Yapıştırıcı üzerinde oluşan von-Mises gerilmesi ve $\mathrm{x}, \mathrm{y}$ ve $\mathrm{z}$ doğrultularında oluşan gerilmeler belirlenen hasar yüklerinde elde edilmiştir. Sonuç olarak, yama boyutlarının, oryantasyon açılarının ve yapış̧ırııının etkileri araştırılmıştır. Gömülü yama ile yapıştırılarak birleştirilen kompozit parçaların hasar yükleri üzerinde en etkili parametrenin yama boyutları olduğu belirlenmiştir.
\end{abstract}

Anahtar kelimeler: Sonlu elemanlar yöntemi, Gerilme analizi, Bağlantı tasarımı, Kompozit parçalar, Hasar analizi.

\section{Stress Analysis of Composite Parts Adhesively Jointed with the Embedded Single-Lap Patch Joint under Tensile Load}

\begin{abstract}
In this paper, composite parts bonded with embedded single-lap patch joint (SLJ) subjected to tensile load were analysed by using three dimensional (3D) finite element method (FEM) based stress analysis. In the analysis, the composite parts were produced using carbon/epoxy (AS4/3501-6) with different fiber orientations and DP410 type were the adhesive used in bonding applications. The models for the numerical analyses were generated in the finite element method based commercial engineering code of ANSYS. Failure loads were determined from the FEA. Stress values at $\mathrm{x}, \mathrm{y}, \mathrm{z}$ directions and the von-Mises stress distributions on adhesive were obtained at the occurrence of the failure for predetermined parameters. Consequently, the effects of orientations, patch dimensions, and adhesive layer were examined. The most effective parameter was determined as the patch dimensions on failure loads of composite parts adhesively bonded with the embedded single-lap patch joint.
\end{abstract}

Keywords: Finite element method, Stress analysis, Joint design, Composite parts, Failure analysis.

\section{Giriş}

Klasik tek tesirli birleştirme yöntemi havacılık, makine tasarımı, otomotiv ve birçok sanayi alanında hasar uğramış parçaların tamiri ve birleştirme işlemleri için tercih edilmektedir. Bu yüzden, bu bağlantı tekniği metal ve kompozit parçalar için geniş bir kullanım alanına sahiptir. Ayrıca yapıştırıcı ve kompozit parçaların sahip oldukları yüksek dayanım, korozyon direnci, kolay uygulanabilirlik gibi birçok özellikler sebebiylede kullanımı gün geçtikçe artmaktadır. Bununla birlikte, kompozit parçaların birleştirilme işleminde güçlü bağlantı durumları önemlidir.

Kompozit parçaların çalışma ömrünü belirlemede kompozitlerin mekanik özellikleri ve hasara uğrama durumlarını belirleme konusunda mekanik davranışları çok önemlidir. Bu yüzden, kompozitler

*Sorumlu yazar: ismail.sulu@inonu.edu.tr

Geliş Tarihi: 17.05.2018, Kabul Tarihi: 10.08.2018 
için birleştirme ve tamir yöntemi önemlidir. Bunan dolayı, literatürde kompozit parçaların tek tesirli birleştirme yöntemi ile yapılan birçok çalışma mevcuttur. Güçlü birleştirme etkisine sahip bağlantı yöntemleri kompozit parçalar için etkin öneme sahiptir. Bu sebepten kompozit parçaların birleştirilmesi alanında bazı çalışmalar yapılmıştır. Abdi ve arkadaşları [1] en düşük yapıştırıcı hasar gerilmesi üzerine çalışmalar yapmışlardır. Buldukları değerleri gerçek gerilme değerleri ile karşılaştırmışlardır. Diğer taraftan, yapıştırılarak birleştirilmiş bağlantının fonksiyonel olarak derecelendirilmiş yapıştırıcı etkisinin geliştirilmesi üzerine çalışmalar yapılmıştır [2,3]. Başka çalışmalarda, deneysel ve nümerik işlemler sonucu tek tesirli birleştirme yöntemi kullanılarak yapılan bağlantı işlemlerinin belirli yüklemeler altında oluşan gerilmeleri incelenmiştir [4,5]. Engerer ve Sancaktar [6] ise tek tesirli birleştirme işlemlerinde oluşan boşlukların etkisini araştırmışlardır. Çalışmalarında iki tür yapıştırıcı kullanmışlardır. Yaptıkları konik bağlantı geometrisinin yapışkan tabaka içinde oluşan soyma gerilmelerini azaltma kabiliyeti oluşturduklarını ifade etmişlerdir. Bu çalışmalara ilave olarak, farklı yüklemeler altında kompozit-kompozit ve kompozit-çelik malzemelerin kullanılarak tek tesirli bindirme yöntemiyle çalışmalarda yapılmıştır [7-12].

$\mathrm{Bu}$ çalışmada, farklı oryantasyon açılarına sahip kompozit parçalar, kompozit yamalar ve yapıştırıcı kullanılmıştır. Farklı oryantasyon açılarında ve yama boyutlarındaki modeller için hasar yükleri belirlenmiştir. Çekme yükü altında gömülü tek tesirli yama ile birleştirilmiş kompozit parçalar lineer olmayan sonlu elemanlar yöntemi ile incelenmiştir. Belirlenen hasar yüklerinde x,y ve z yönlerinde gerilmeler, kayma gerilmeleri ve von-Mises gerilmeleri elde edilmiştir. Yapıştırma yönteminin estetik boyutu ve sanayide kolay uygulanabilirliği ifade edilmiştir. Ayrıca, bu birleştirme yönteminin avantajları gösterilmiştir.

\section{Malzeme ve Metot}

Çekme yüke altında gömülü yama ile birleştirilmiş kompozit parçaların modeli Şekil 1'de gösterilmiştir. Sonlu elemanlar analizi için kompozit parçalar dokuz tabakadan ve yamalar ise üç tabakadan oluşturulmuştur. Ayrıca yapıştırıcı olarak da DP 410 kullanılmıştır. Kompozit parçaların ve yapıştırıcının mekanik özellikleri Tablo 1 ve Tablo 2'de gösterilmiştir. Tablo 3'de gösterilen oryantasyon açıları kullanılmıştır. Ayrıca Şekil 2'de yapıştırıcı için gerilme-gerinin eğrisi gösterilmiştir.

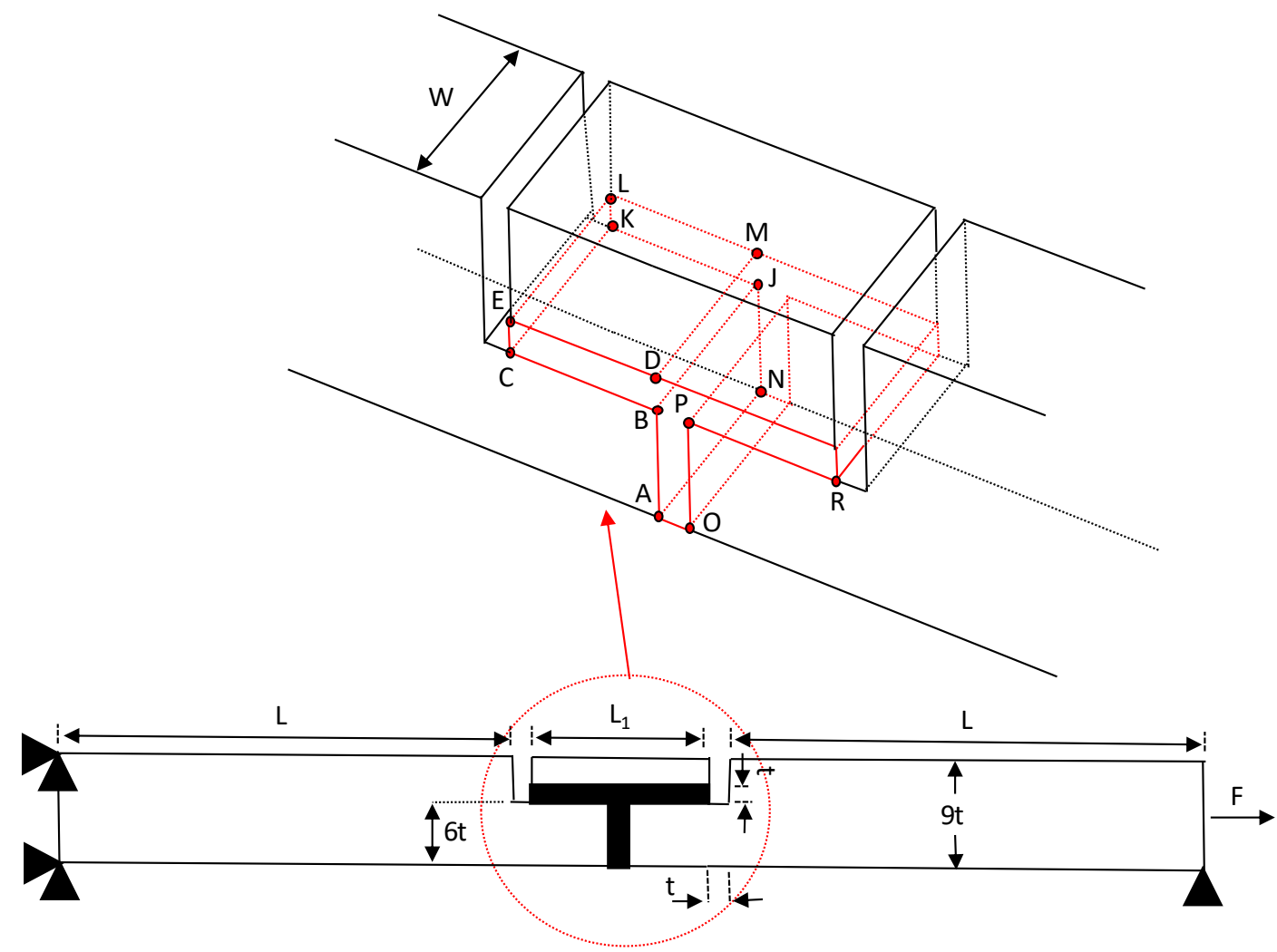

Şekil 1. Gömülü tek tesirli yama ile yapıştırılarak birleştirilmiş kompozit parçalar 
Karbon fiber takviyeli kompozit parçaların kalınlığ 9 x0.2 mm ve her bir tabaka kalınlığı 0.2 mm'dir. Ayrıca yapıştırıcı tabaka kalınlığı $0.2 \mathrm{~mm}(\mathrm{t})$ 'dir. Kompozit parçaların uzunluğu $62.5 \mathrm{~mm}(\mathrm{~L})$, yama toplam uzunluğu $15 \mathrm{~mm}, 20 \mathrm{~mm}$ ve $25 \mathrm{~mm}\left(\mathrm{~L}_{1}\right)^{\prime}$ dir.

Tablo 1. AS4/3501-6 karbon/epoksi için malzeme özellikleri [13-15]

\begin{tabular}{lc}
\hline Özellikler & Karbon/epoksi (AS4/3501-6) \\
\hline $\mathrm{E}_{\mathrm{x}}(\mathrm{MPa})$ & 113600 \\
$\mathrm{E}_{\mathrm{y}}(\mathrm{MPa})$ & 9650 \\
$\mathrm{E}_{\mathrm{z}}(\mathrm{MPa})$ & 9650 \\
$\mathrm{G}_{\mathrm{xy}}(\mathrm{MPa})$ & 6000 \\
$\mathrm{G}_{\mathrm{yz}}(\mathrm{MPa})$ & 3800 \\
$\mathrm{G}_{\mathrm{xz}}(\mathrm{MPa})$ & 6000 \\
$v_{\mathrm{xy}}$ & 0.334 \\
$v_{\mathrm{yz}}$ & 0.54 \\
$v_{\mathrm{xz}}$ & 0.328 \\
$\mathrm{X}_{\mathrm{T}}(\mathrm{MPa})$ & 1720 \\
$\mathrm{Y}_{\mathrm{T}}(\mathrm{MPa})$ & 55.2 \\
$\mathrm{Z}_{\mathrm{T}}(\mathrm{MPa})$ & 55.2 \\
$\mathrm{X}_{\mathrm{C}}(\mathrm{MPa})$ & 1170 \\
$\mathrm{Y}_{\mathrm{C}}(\mathrm{MPa})$ & 207 \\
$\mathrm{Z}_{\mathrm{C}}(\mathrm{MPa})$ & 207 \\
$\mathrm{~S}_{\mathrm{xy}}(\mathrm{MPa})$ & 103 \\
$\mathrm{~S}_{\mathrm{yz}}(\mathrm{MPa})$ & 82.7 \\
$\mathrm{~S}_{\mathrm{xz}}(\mathrm{MPa})$ & 82.7 \\
\hline
\end{tabular}

Tablo 2. DP 410 yapıştırıcı için malzeme özellikleri $[16,17]$

\begin{tabular}{c|c}
\hline & DP 410 \\
Yapıştırıcı \\
\hline Elastik modül $\mathrm{E}_{\mathrm{a}}(\mathrm{MPa})$ & 2567.45 \\
Poisson oranı $v_{e}$ & 0.31 \\
Akma mukavemeti $\sigma_{\mathrm{y}}(\mathrm{MPa})$ & 38 \\
Maksimum çekme mukavemeti $\sigma_{\mathrm{t}}(\mathrm{MPa})$ & 40.79 \\
Maksimum çekme gerinimi $\varepsilon_{\mathrm{t}}\left(\mathrm{mm} \cdot \mathrm{mm}^{-1}\right)$ & 0.027 \\
\hline
\end{tabular}

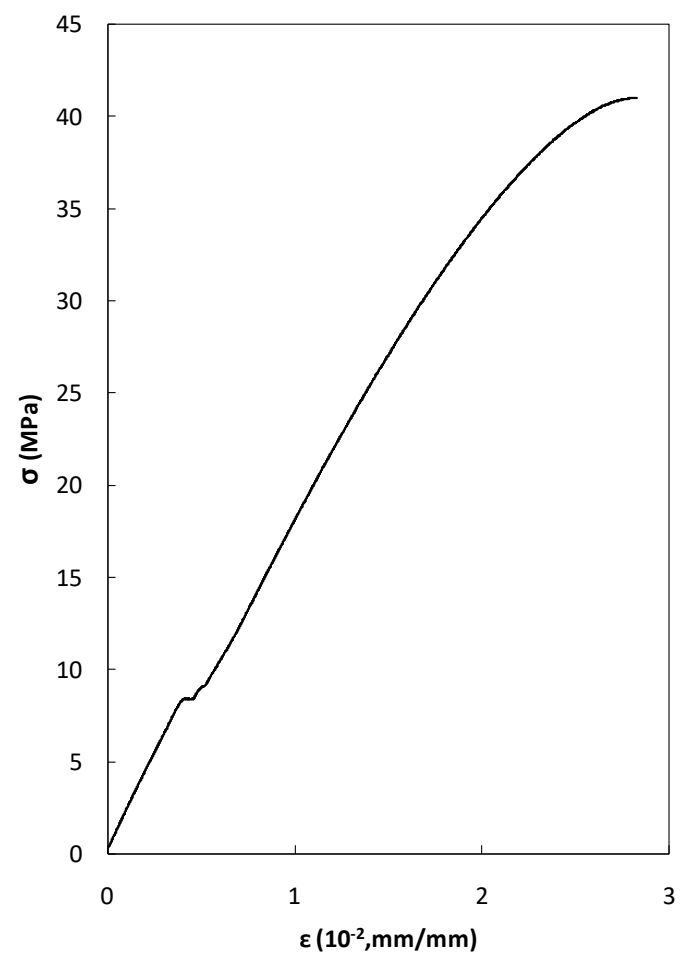

Şekil 2. DP 410 yapış̧ıııcı için gerilme-gerinim eğrisi $[16,17]$ 
Tablo 3. Çalışmalarda kullanılan oryantasyon açıları

\begin{tabular}{c}
\hline Oryantasyon açlar1 $\left({ }^{0}\right)$ \\
15/-15/0/0/0/0/0/0/0 \\
30/-30/30/-30/30/-30/30/-30/30 \\
$45 /-45 / 45 /-45 / 45 /-45 / 45 /-45 / 45$ \\
$60 /-60 / 60 /-60 / 60 /-60 / 60 /-60 / 60$ \\
$75 /-75 / 75 /-75 / 75 /-75 / 75 /-75 / 75$ \\
$90 / 90 / 90 / 90 / 90 / 90 / 90 / 90 / 90$
\end{tabular}

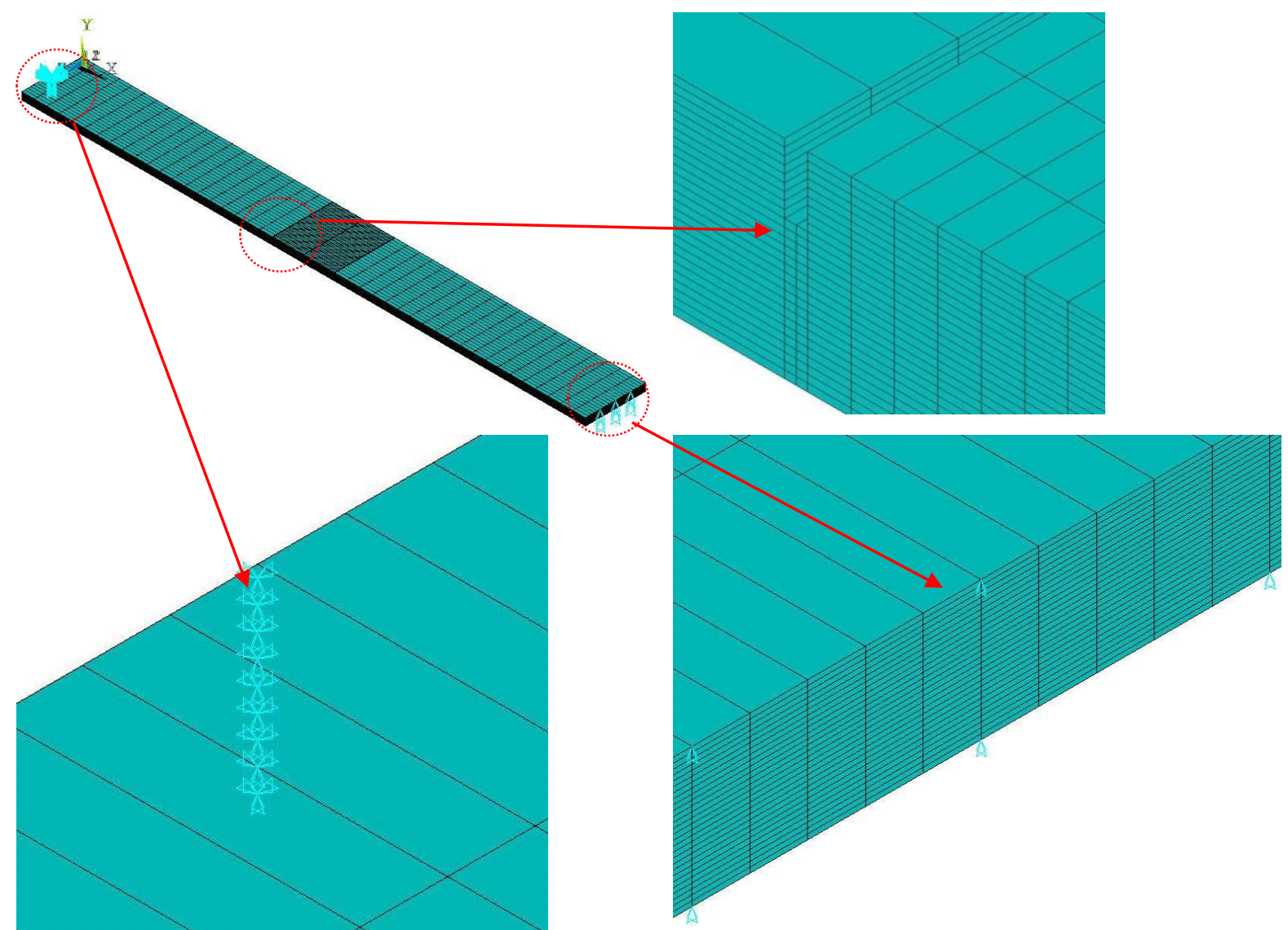

Şekil 3. Mesh detayları ve sınır şartları

Sonlu elemanlar çalışmasında, çekme yüküne maruz bırakılmış gömülü yama ile birleştirilmiş kompozit parçalar sonlu elemanlar yöntemi ile simüle edilmiştir. Üç boyutlu lineer olmayan sonlu elemanlar modeli ANSYS paket programında 20 nodlu izoparametrik dört köşeli eleman tipi olan solid186 model elemanlarla modellenmiştir. Şekil 1'de görülen kompozit modelin bir ucu x, y ve z yönlerinde sabitlenmiş, diğer ucu ise sadece y yönünde sabitlenmiştir. Bağlantı görünümü, sınır koşulları ve mesh detayları Şekil 3'de gösterilmiştir. Çekme yüküne maruz bırakılmış gömülü yama ile birleştirilmiş kompozit parçaların gerilme analizleri yapılırken kompozit parçalar ortotropik malzeme olduğundan Tsai-wu hasar kriteri, yapıştırıcı ise izotropik malzeme olduğu için von-Mises hasar kriteri dikkate alınmıştır [16-18]. 


\section{Bulgular ve Tartışma}

\subsection{Oryantasyon açılarının ve yama boyutlarının gerilme dağılımı üzerine etkisi}

Çekme yüküne maruz gömmeli yama ile birleştirilmiş kompozit parçaların gerilme dağılımları karşılaştırılmıştır. Tablo 3' de gösterilen oryantasyon açıları kullanılmıştır. Şekil 1'de görüldüğü gibi bağlantı bölgesinde birçok gerilme hattı bulunmaktadır. Bu gerilme hatlarında bazıları birbirine yakın, hatta aynı gerilme dağılımlarına sahip gerilme hatları mevcuttur.

Çalışmanın sağlıklı bir şekilde yürütülmesi ve hasarın oluşumunda kritik durum oluşturan gerilme hattının belirlenmesi çalışması yapılmıştır. Şekil 4(a)-(c)'de görüldüğü gibi, bazı gerilme hatlarındaki gerilmelerin çok yakın olduğu, bazı gerilme hatlarının da simetrik olduğu için benzer denecek oranda gerilme değerlerine sahip oldukları görülmektedir. Şekil 4(d) 'de görüldüğü üzere, AB, B-C, D-E, A-N, B-J, C-K ve E-L gerilme hatlarının birbirinden farklı gerilme dağılımlarına sahiptir. Bundan dolayı, bu gerilme hatları karşılaştırılmış ve maksimum gerilmenin C-K Gerilme hattı üzerinde oluştuğu tespit edilmiştir ve her bir parametre durumu için C-K Gerilme hattı üzerindeki gerilmeler incelenmiştir.

$20 \mathrm{~mm}$ yama uzunluğu dikkate alınarak oryantasyon açılarının gerilme dağılımları üzerine etkileri karşılaştııılmıştır. Her bir gerilme durumunda hangi oryantasyon açısının daha etkili olduğu Şekil 5 ve Şekil 6 'da görülmektedir. $\sigma_{\mathrm{x}}$ ve $\sigma_{\mathrm{y}}$ gerilmelerinde maksimum gerilmenin elde edildiği $90^{\circ} / 90^{\circ} / 90^{\circ} / 90^{\circ} / 90^{\circ} / 90^{\circ} / 90^{\circ} / 90^{\circ} / 90^{\circ}$ oryantasyon açısına sahip kompozit parçaların birleştirilmesinde meydana geldiği görülmektedir. Diğer taraftan, $\sigma_{\mathrm{y}}$ gerilme dağılımı incelendiğinde,

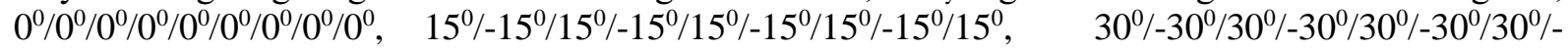
$30^{0} / 30^{0}$ ve $45^{\%} /-45^{\circ} / 45^{\%} /-45^{\circ} / 45^{\%} /-45^{\circ} / 45^{\circ} /-45^{0} / 45^{\circ}$ oryantasyon aç1larına sahip kompozit parçalardan tasarlanmış modeller üzerindeki $\sigma_{y}$ gerilmesi bir birine yakın görünse de, $0^{0} / 0^{0} / 0^{0} / 0^{0} / 0^{0} / 0^{0} / 0^{0} / 0^{0} / 0^{0}$ oryantasyon açısında oluşan gerilmelerin diğerlerinde daha büyük değerlere ulaştığı görülmektedir. Şekil 5 (d) incelendiğinde, bazı oryantasyon açılarında gerilme dağılımlarındaki değişimin çok

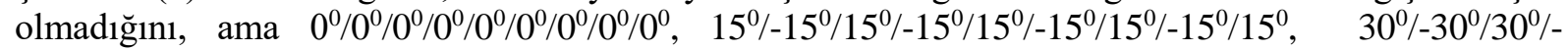

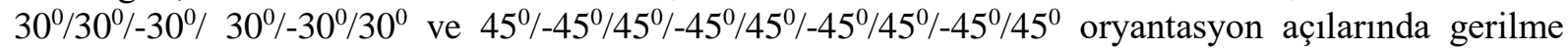
dağılımlarında büyük değişimler gösterdiği görülmektedir. Fakat $\sigma_{\text {eqv }}$ gerilme dağılımının $90^{\circ} / 90^{\circ} / 90^{\circ} / 90^{\circ} / 90^{\circ} / 90^{\circ} / 90^{\circ} / 90^{\circ} / 90^{\circ}$ oryantasyon açısında maksimum olduğu gösterilmiştir. Şekil $6^{\prime} \mathrm{da}$ kayma gerilmeleri incelendiğinde, $\sigma_{\mathrm{xy}}$ gerilmesi $90^{\circ} / 90^{\circ} / 90^{\circ} / 90^{\circ} / 90^{\circ} / 90^{\circ} / 90^{\circ} / 90^{\circ} / 90^{\circ}$ oryantasyon açısında maksimum değerlere ulaştı̆̆ görülmektedir. $\sigma_{\mathrm{xz}}$ incelendiğinde, maksimum değişimin $0^{\circ} / 0^{0} / 0^{\circ} / 0^{0} / 0^{\circ} / 0^{\circ} \% 0^{0} / 0^{0} / 0^{0}$ oryantasyon açısında meydana geldiği görülmektedir. Son olarak, $\sigma_{\mathrm{yz}}$ gerilmesi

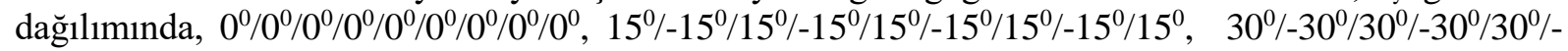
$30^{\circ} / 30^{\%} /-30^{\circ} / 30^{\circ}$ oryantasyon açılarında gerilme dağılımları birbirlerine yakın görünmesine rağmen, maksimum gerilme dağılımları $0^{0} / 0^{0} / 0^{0} / 0^{\circ} / 0^{0} / 0^{\circ} / 0^{0} / 0^{\circ} / 0^{0}$ oryantasyon açısında meydana geldiği Şekil 6 (c)'de görülmektedir. 


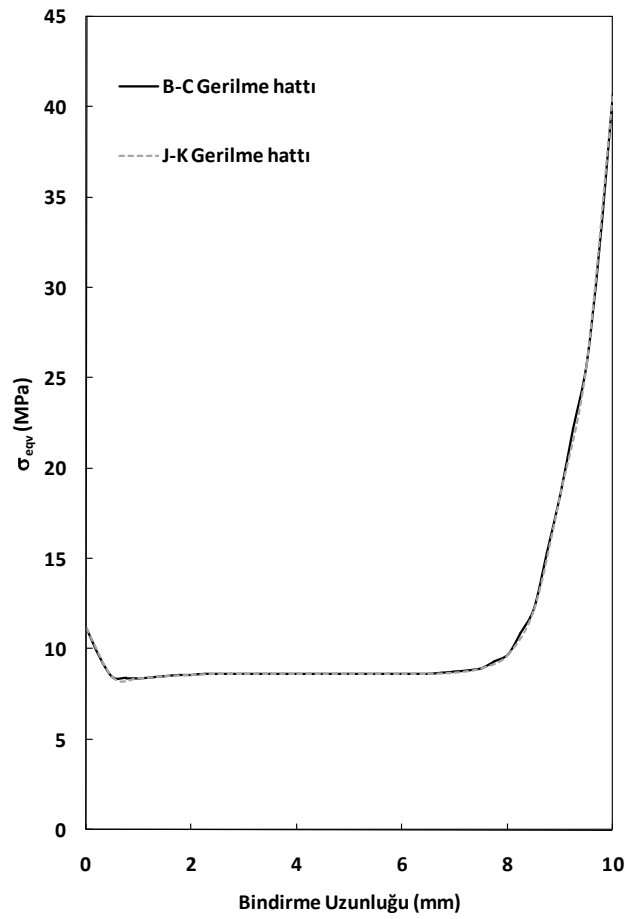

(a)

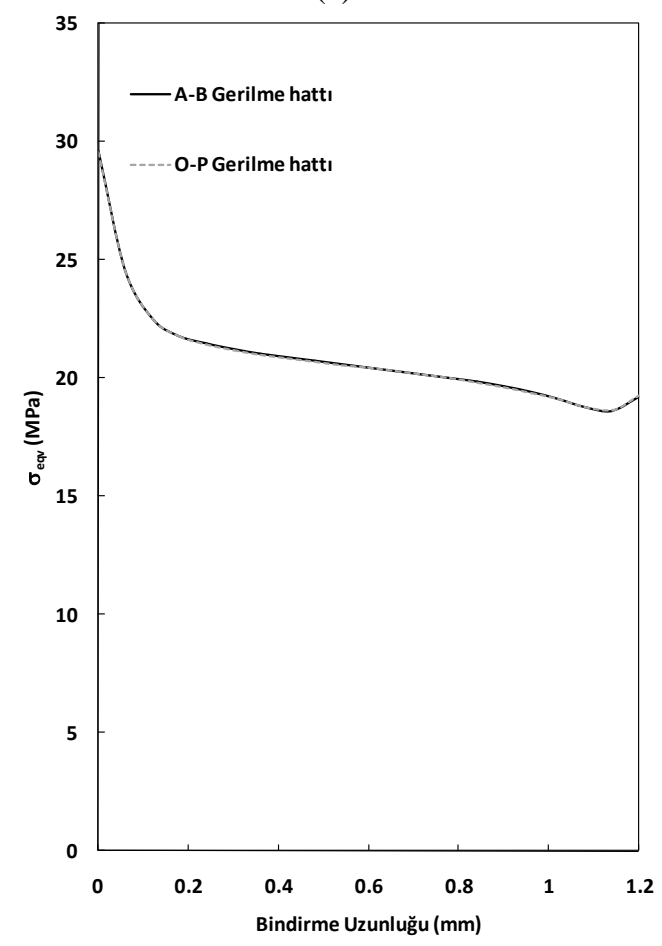

(c)

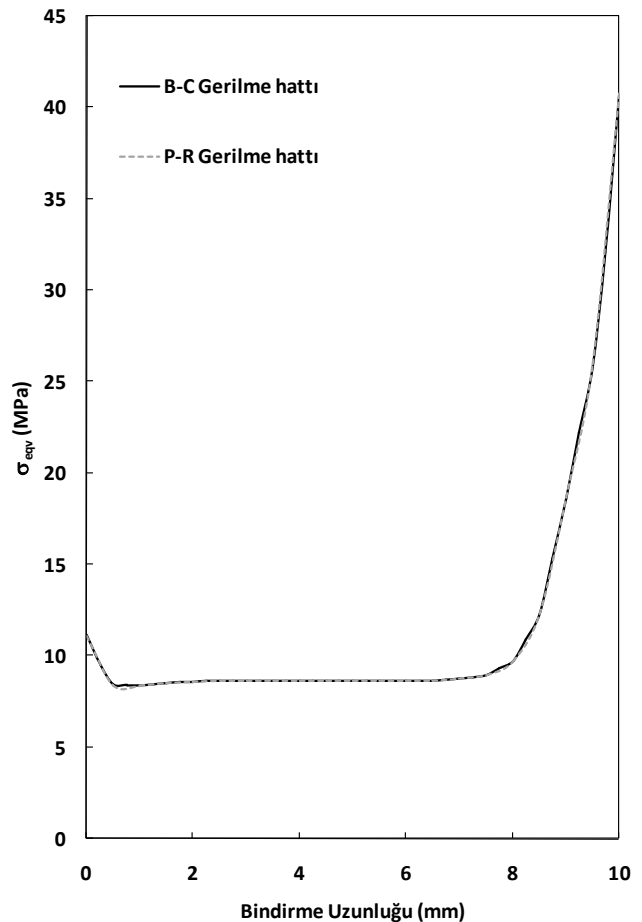

(b)

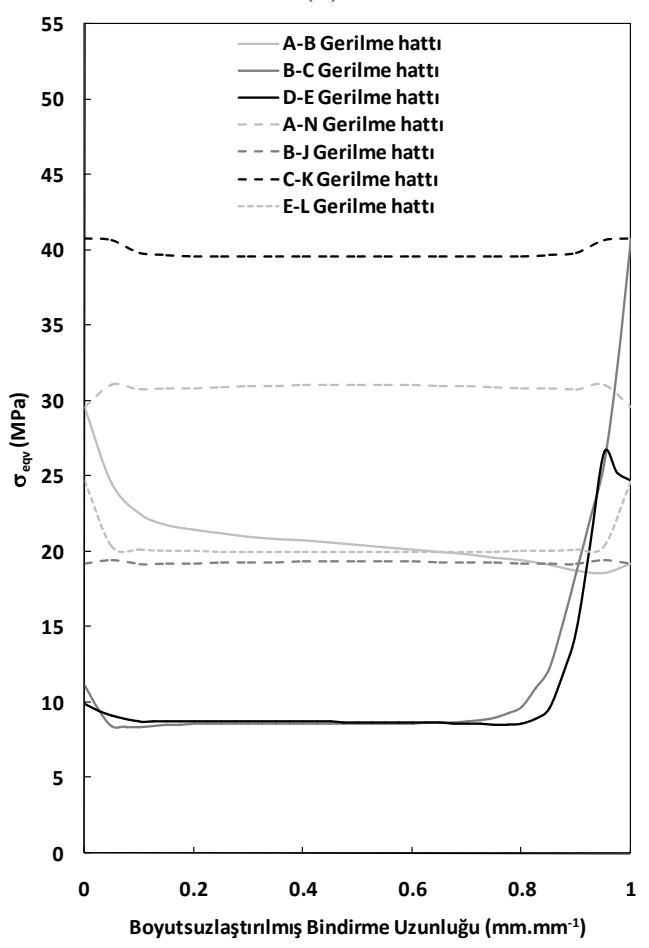

(d)

Şekil 4. Farklı gerilme boyunca von-Mises gerilmeleri(Şekil 1'de gösterilen: $20 \mathrm{~mm}$ yama boyunda ve $0^{0} / 0^{0} / 0^{0} / 0^{0} / 0^{0} / 0^{0} / 0^{0} / 0^{0} / 0^{0}$ için yapıştırıcı bölgesinde karşılaştırma 


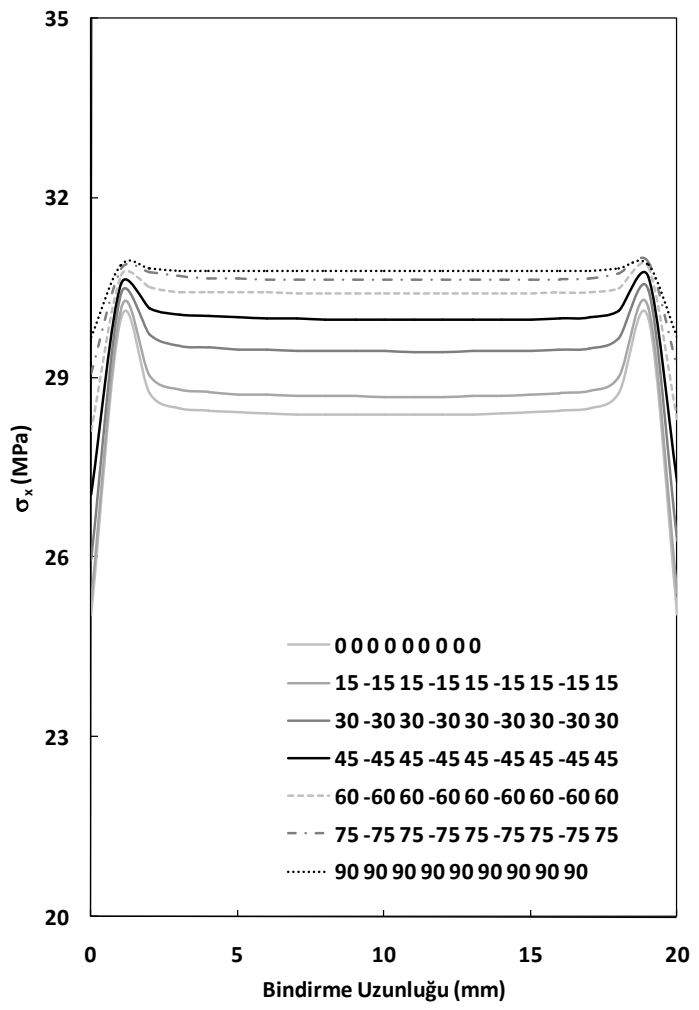

(a)

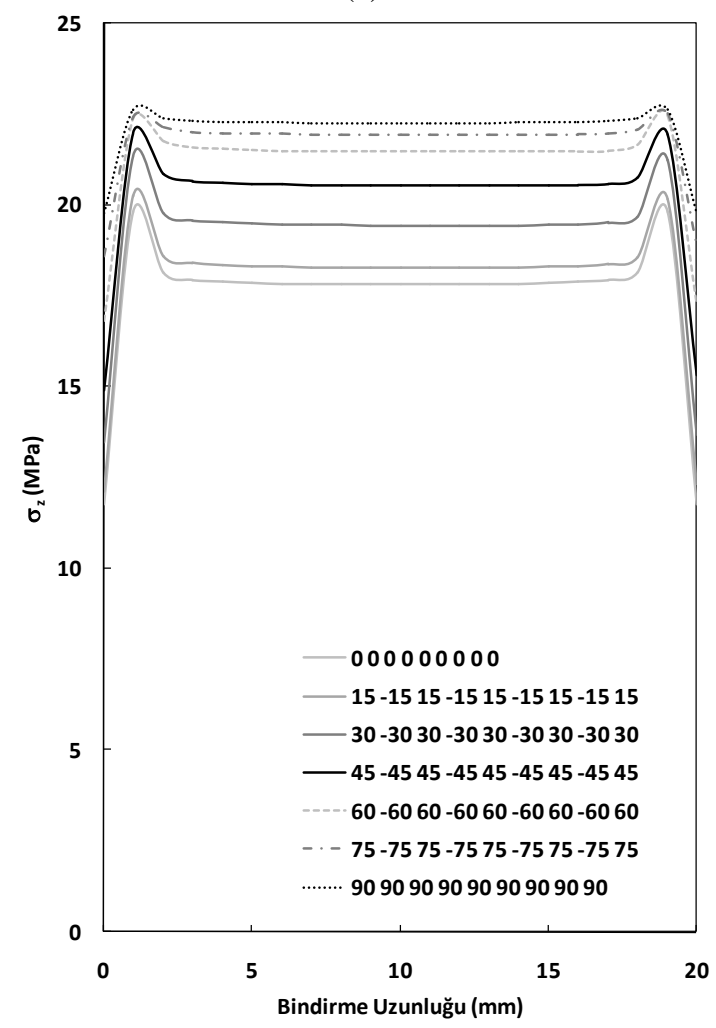

(c)

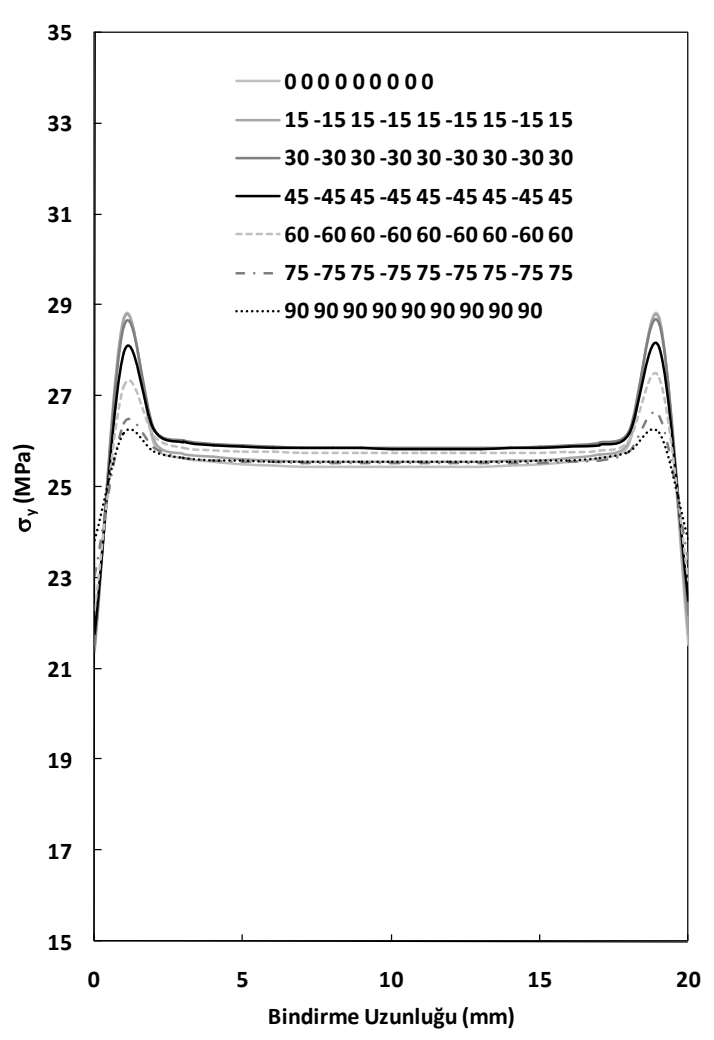

(b)

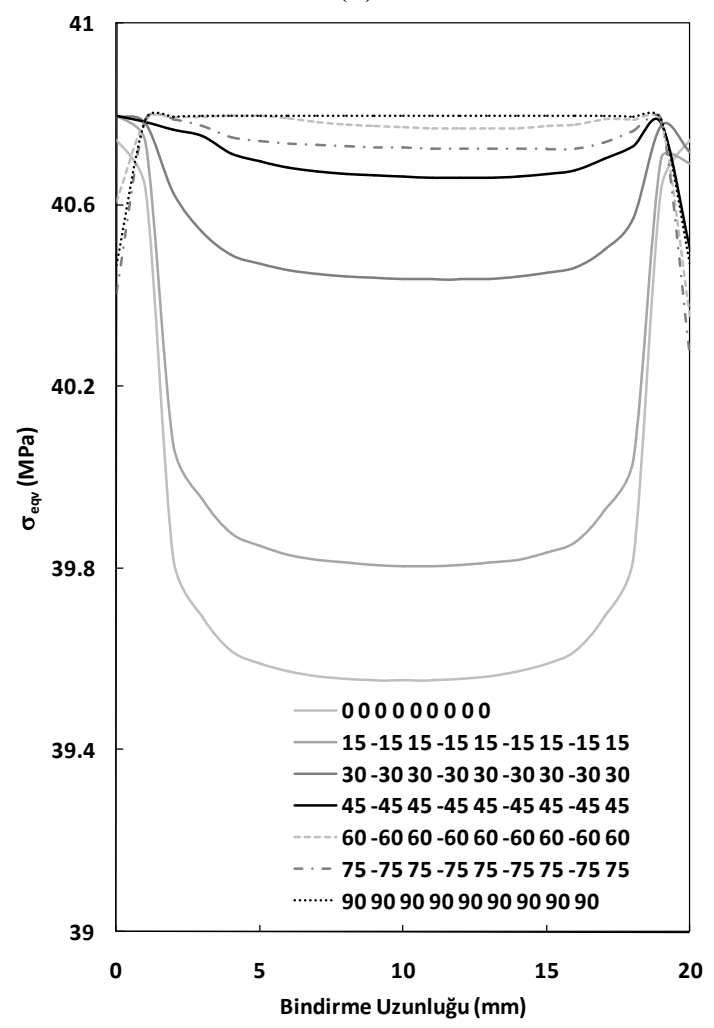

(d)

Şekil 5. $20 \mathrm{~mm}$ yama uzunluğunda yapıştırıcı tabaka üzerindeki C-K Gerilme hattı boyunca tüm oryantasyon açıları için gerilme dağılımlarının karşılaştırılması, a) $\sigma_{x}$, b) $\sigma_{y}$, c) $\sigma_{z}$, d) $\sigma_{\text {eqv }}$ 


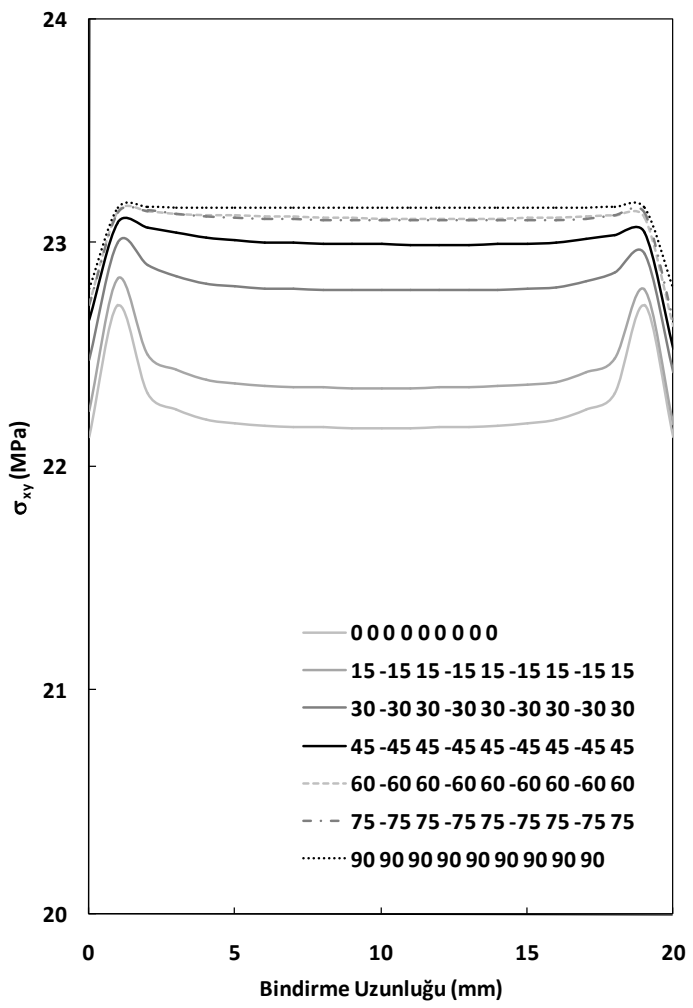

(a)

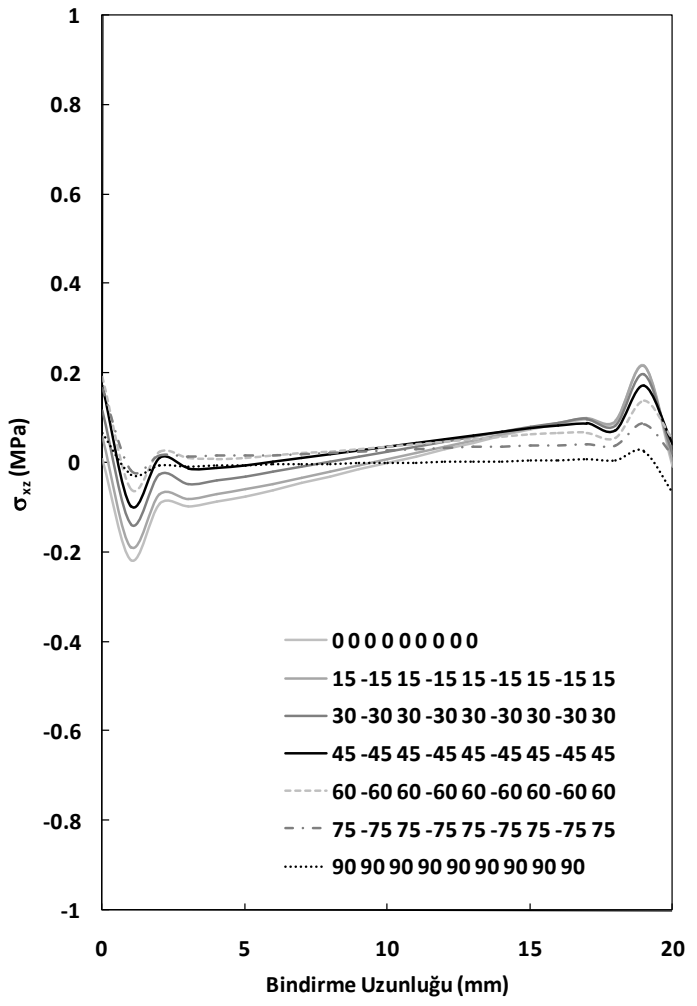

(b)

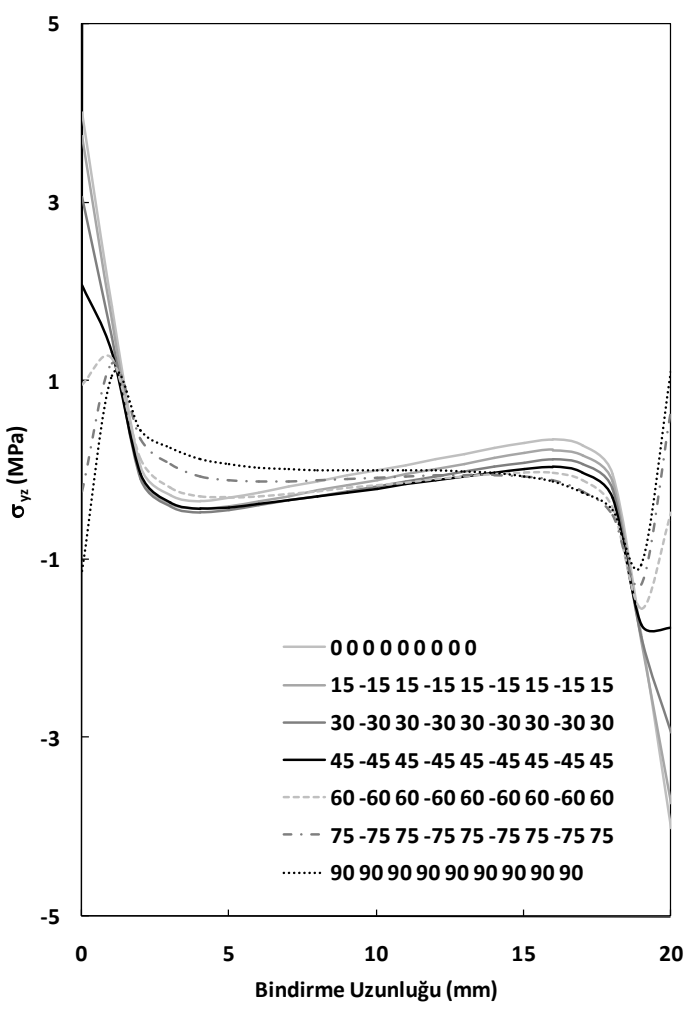

(c)

Şekil 6. $20 \mathrm{~mm}$ yama uzunluğunda yapıştırıcı tabaka üzerindeki C-K Gerilme hattı boyunca tüm oryantasyon açıları için kayma gerilme dağılımlarının karşılaştırılması, a) $\sigma_{x y}$, b) $\sigma_{x z}$, c) $\sigma_{y z}$

Genel olarak Şekil 5 ve 6'ya bakıldığında oryantasyon açılarının gerilme dağılımlarına etkisinin olduğu görülmektedir. Ayrıca oryantasyon açılarının her bir gerilme üzerinde etkilerinin farklı olduğunun, bazı gerilmelerde de oryantasyon açılarının etkilerinin yakın olmasına rağmen farklılıkların olduğu Şekil 5 ve Şekil 6'da gösterilmiştir. 
Şekil 7 incelendiğinde, $0^{0} / 0^{0} / 0^{\circ} / 0^{0} / 0^{0} / 0^{0} / 0^{0} / 0^{0} / 0^{0}$ oryantasyon açısında üç farklı yama uzunluklarında yapıştırıcı üzerinde $\mathrm{C}-\mathrm{K}$ Gerilme hattı boyunca oluşan von-Mises gerilmeleri karşılaştırılmıştır. Maksimum gerilmenin $15 \mathrm{~mm}$ yama uzunluğunda medya geldiği görülmektedir. $\mathrm{Bu}$ durumda, yama uzunluğunun da gerilme dağılımlarına etkisinin büyük oranda olduğu söylenebilir.

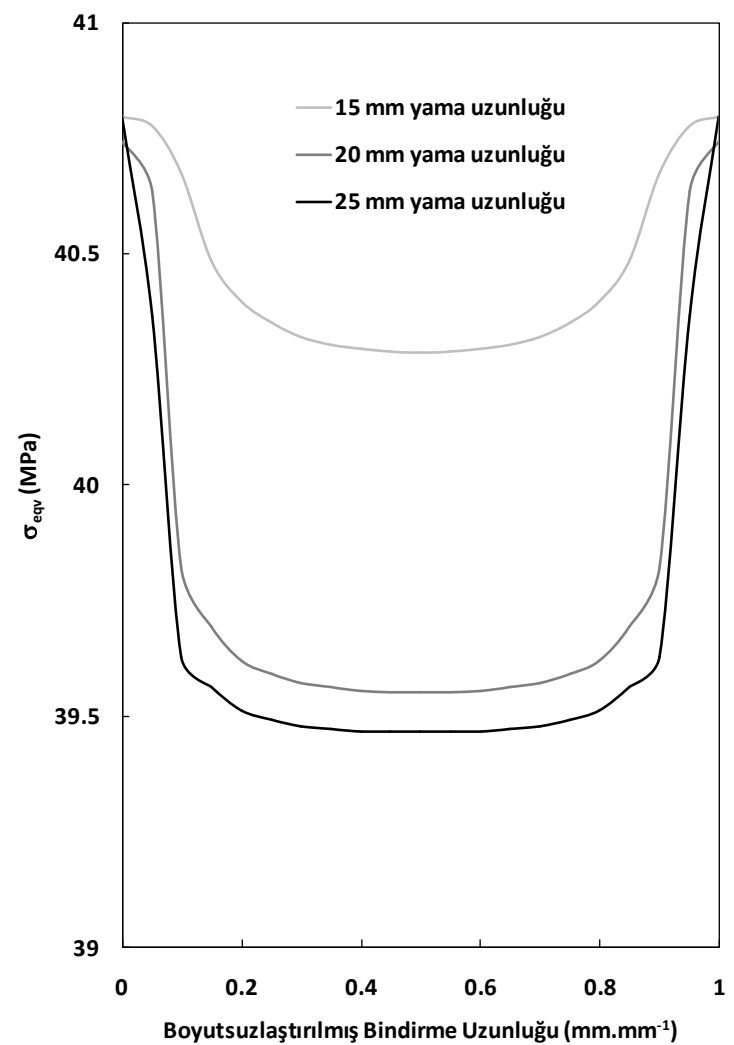

Şekil 7. $0^{0} / 0^{0} / 0^{0} / 0^{0} / 0^{0} / 0^{0} / 0^{0} / 0^{\circ} / 0^{0}$ için C-K Gerilme hattı boyunca farklı yama boylarında von-Mises gerilme dağılımlarının karşılaştırılması (Şekil 1'de gösterilmiştir)

\subsection{Oryantasyon açılarının ve yama boyutlarının hasar yükü üzerine etkisi}

Çekme yükü altında gömülü tek tesirli yama ile birleştirilmiş kompozit parçaların hasar yükleri Tablo 4'de gösterilmiştir. Yapıştırıcının gerilme-gerinim eğrisi de Şekil 2'de gösterilmiştir. Ayrıca, hasar yükünü belirlenmesi için Tablo 2'de yapıştırıcının maksimum çekme mukavemeti ve maksimum çekme gerinim değerleri verilmiştir. Yapıştırıcı için von-Mises hasar kriteri, kompozit için Tsai-wu hasar kriterleri dikkate alınmıştır. Tüm hasarların yapıştırıcı bölgede meydan geldiğinden von-Mises hasar kriterinin kullanımıyla hesaplanan $\sigma_{\text {eqv }}$ ve $\varepsilon_{\text {eqv }}$ değerleri vasıtasıyla hasar yükleri analizler sonucu elde edilmiştir. Sonlu elemanlar analizi çözümlerinde, malzemenin lineer olmayan bir davranış sergilemiştir ve uygulanan yükün ise belirli aralıklarla artırılarak hasar yükleri belirlenmiştir. Bu artışlar tüm modeller üzerinde birim alana $0.5 \mathrm{~N} / \mathrm{mm}^{2}$ yük artışları şeklinde uygulanmıştır. Kalan yük son adımda uygulanarak hasar yükleri belirlenmiştir [16,17,19]. 
Tablo 4. DP 410 kullanıldığında nümerik analiz sonuçları

\begin{tabular}{|c|c|c|c|}
\hline $\begin{array}{c}\text { Numune } \\
\text { Numaras1 }\end{array}$ & $\begin{array}{c}\text { Bindirme } \\
\text { Uzunluğu (mm) }\end{array}$ & $\begin{array}{c}\text { Oryantasyon Açısı } \\
\left({ }^{0}\right)\end{array}$ & $\begin{array}{c}\text { Hasar Yükü } \\
(\mathrm{N})\end{array}$ \\
\hline 1 & \multirow{7}{*}{15} & 0000000000000 & 8019.0 \\
\hline 2 & & $\begin{array}{lllllllll}15 & -15 & 15 & -15 & 15 & -15 & 15 & -15 & 15\end{array}$ & 8019.0 \\
\hline 3 & & 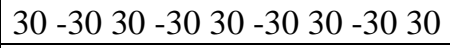 & 7897.5 \\
\hline 4 & & 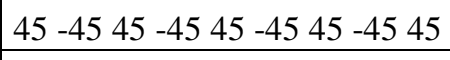 & 7776.0 \\
\hline 5 & & $60-6060-6060-6060-6060$ & 7654.5 \\
\hline 6 & & $75-7575-7575-7575-7575$ & 7533.0 \\
\hline 7 & & 909090909090909090 & 7411.5 \\
\hline 8 & \multirow{7}{*}{20} & 000000000000 & 11178.0 \\
\hline 9 & & $\begin{array}{lllllllll}15 & -15 & 15 & -15 & 15 & -15 & 15 & -15 & 15\end{array}$ & 11178.0 \\
\hline 10 & & $30-3030-30 \begin{array}{llllll}30 & -30 & 30 & -30 & 30 \\
\end{array}$ & 11178.0 \\
\hline 11 & & 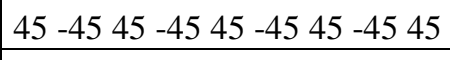 & 11016.0 \\
\hline 12 & & $60-6060-6060-6060-6060$ & 10854.0 \\
\hline 13 & & $\begin{array}{lllllllllll}75 & -75 & 75 & -75 & 75 & -75 & 75 & -75 \\
\end{array}$ & 10692.0 \\
\hline 14 & & 909090909090909090 & 10692.0 \\
\hline 15 & \multirow{7}{*}{25} & 0000000000000 & 14782.5 \\
\hline 16 & & $\begin{array}{lllllllll}15 & -15 & 15 & -15 & 15 & -15 & 15 & -15 & 15\end{array}$ & 14580.0 \\
\hline 17 & & 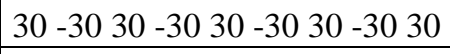 & 14580.0 \\
\hline 18 & & 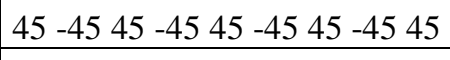 & 14377.5 \\
\hline 19 & & $60-6060-6060-6060-6060$ & 14377.5 \\
\hline 20 & & $75-7575-7575-7575-7575$ & 14175.0 \\
\hline 21 & & 909090909090909090 & 14175.0 \\
\hline
\end{tabular}

Tüm gerilmeler ve von-Mises gerilmeleri nümerik olarak elde edilmiş çekme hasar yükü değerleri kullanılarak elde edilmiştir. Şekil 4'de görüldüğü gibi, kompozit parçalarla yapıştırıcı ara yüzeyleri arasındaki gerilme hatlarında $\mathrm{C}-\mathrm{K}$ Gerilme hattının maksimum değerde olduğu tespit edilmiștir.

Tablo 4 incelendiğinde, yama boyunun ve oryantasyon açılarının hasar yükleri üzerindeki etkileri görülmektedir. $25 \mathrm{~mm}$ yama uzunluğunda maksimum hasar yüklerinin elde edilmiştir. Yama boylarının değişimi ile oryantasyon açılarının etkisinde değiştiği gözlemlenmiştir. Genel olarak $0^{0} / 0^{0} / 0^{0} / 0^{0} / 0^{0} / 0^{0} / 0^{0} / 0^{0} / 0^{0}$ oryantasyon açısındaki tüm yama uzunluklarında maksimum hasar yüklerin elde edildiğini ve $90^{\circ} / 90^{\circ} / 90^{\circ} / 90^{\circ} / 90^{\circ} / 90^{\circ} / 90^{\circ} / 90^{\circ} / 90^{\circ}$ oryantasyon açısında da minimum hasar yüklerinin elde edildiği görülmektedir. Maksimum ve minimum hasar yüklerinin bu oryantasyon açılarına yakın oryantasyon açılarında da kısmen görüldüğü tespit edilmiştir. Bunun sebebi, yapıştırma işlemlerinde bir birine yakın oryantasyon açılı modellerin benzer hasar yüklerine ulaşabilirliğinin olduğu söylenebilir.

\section{Sonuçlar ve Öneriler}

Bu çalışmada, çekme yüküne maruz bırakılmış gömülü yama ile yapıştırılarak birleştirilmiş kompozit parçaların hasar yükleri ve gerilme analizleri incelenmiştir. Sonuçlar aşağıdaki gibidir:

- Şekil 4'de görüldüğü gibi, C-K maksimum gerilme hattı olduğu belirlenmiştir.

- $\sigma_{\mathrm{x}}$ ve $\sigma_{\mathrm{y}}$ gerilmelerinde maksimum gerilmenin elde edildiği $90^{\circ} / 90^{\circ} / 90^{\circ} / 90^{\circ} / 90^{\circ} / 90^{\circ} / 90^{\circ} / 90^{\circ} / 90^{\circ}$ oryantasyon açısına sahip kompozit parçaların birleştirilmesinde meydana geldiği görülmektedir.

- $\sigma_{y}$ gerilme dağ 11 ımı incelendiğinde, $0^{0} / 0^{\circ} / 0^{\circ} / 0^{\circ} / 0^{0} / 0^{0} / 0^{\circ} / 0^{0} / 0^{0}$ oryantasyon açısında oluşan gerilmelerin diğerlerinde daha büyük değerlere ulaştığı görülmektedir. 
- $\sigma_{\text {eqv }}$ gerilme dağ 11 mıının $90^{\circ} / 90^{\circ} / 90^{\circ} / 90^{\circ} / 90^{\circ} / 90^{\circ} / 90^{\circ} / 90^{\circ} / 90^{\circ}$ oryantasyon açısında maksimum olduğu belirlenmiştir.

- Şekil 6' da, $\sigma_{\mathrm{xy}}$ gerilmesi $90^{\circ} / 90^{\circ} / 90^{\circ} / 90^{\circ} / 90^{\circ} / 90^{\circ} / 90^{\circ} / 90^{\circ} / 90^{\circ}$ oryantasyon açısında, $\sigma_{\mathrm{xz}}$ ve $\sigma_{\mathrm{yz}}$ gerilmeleri de $0^{0} / 0^{0} / 0^{0} / 0^{0} \% 0^{\circ} / 0^{\circ} / 0^{0} / 0^{\circ} / 0^{0}$ oryantasyon açısında maksimum değerlere ulaştığ görülmektedir.

- Maksimum von-Mises gerilme dağılımın 15 mm yama uzunluğunda el edildiği Şekil 7'de gösterilmiştir.

- Gömülü yama kullanılarak yapıştırıcı ile birleştirme yönteminde yama uzunluğu değiş̧tikçe hasar yükünde değiştiği tespit edildi ve maksimum hasar yüklerinin $25 \mathrm{~mm}$ yama uzunluğunda elde edildiği Tablo 4' de gösterilmiştir.

- Oryantasyon açılarının da hasar yükü üzerine yama uzunlukları gibi etkili parametre olduğu Tablo 4'de görülmektedir. $10^{0} / 0^{0} / 0^{0} / 0^{\circ} / 0^{0} / 0^{0} / 0^{\circ} / 0^{0}$ oryantasyon açısındaki tüm yama uzunluklarında maksimum hasar yüklerin elde edildiğini ve $90^{\circ} / 90^{\circ} / 90^{\circ} / 90^{\circ} / 90^{\circ} / 90^{\circ} / 90^{\circ} / 90^{\circ} / 90^{\circ}$ oryantasyon açısında da minimum hasar yüklerinin elde edildiği görülmektedir.

- Genel olarak, tüm modellerde kompozit parçalar ve yamalar daha dayanıklı olduğundan hasar yapıştırıcı bölgede oluşmuş̧tur.

- Hasar yükü üzerinde en etkili parametrenin yama boyutları olduğu tespit edilmiştir.

Sonuç olarak yama boyunun ve oryantasyon açılarının yapıştırıcı kullanarak birleştirmede etkili parametreler olduğu gösterilmiştir. Yüksek dayanımlı birleştirmeler elde etmek istendiğinde fiber doğrultusu $0^{0} / 0^{\circ} / 0^{0} / 0^{0} \% 0^{0} / 0^{\circ} / 0^{\circ} / 0^{0} / 0^{0}$ oryantasyon tabaka diziliminde üretilmiş kompozit parçaların kullanılması ve yapıştırılan yüzeyin geniş olması gerektiği bu çalışma ile ifade edilmiştir.

\section{Kaynaklar}

[1] Abdi H., Papadopoulos J., Nayeb-Hashemi H., Vaziri A. 2017. Enhanced elastic-foundation analysis of balanced single lap adhesive joints, International Journal of Adhesion \& Adhesives, 72: 80-91.

[2] Stein N., Mardani H., Becker W. 2016. An efficient analysis model for functionally graded adhesive single lap joints, International Journal of Adhesion \& Adhesives, 70: 117-125.

[3] Guin W.E., Wang J. 2016. Theoretical model of adhesively bonded single lap joints with functionally graded adherents, Engineering Structures, 124: 316-332.

[4] Moya-Sanz E.M., Ivañez I., Garcia-Castillo S.K. 2017. Effect of the geometry in the strength of single-lap adhesive joints of composite laminates under uniaxial tensile load, International Journal of Adhesion \& Adhesives, 72: 23-29.

[5] Ribeiro T.E.A., Campilho R.D.S.G., da Silva L.F.M., Goglio L. 2016. Damage analysis of composite-aluminium adhesively-bonded single-lap joints, Composite Structures, 136: 25-33.

[6] Engerer J.D., Sancaktar E. 2011. The effects of partial bonding in load carrying capacity of single lap joints, International Journal of Adhesion \& Adhesives, 31: 373-379.

[7] Tang J.H., Sridhar I., Srikanth N. 2013. Static and fatigue failure analysis of adhesively bonded thick composite single lap joints, Composites Science and Technology, 86: 18-25.

[8] Kim K.S., Yi Y.M., Cho G.R., Kim C.G. 2008. Failure prediction and strength improvement of uni-directional composite single lap bonded joints, Composite Structures, 82: 513-520.

[9] Katnam K.B., Comer A.J., Stanley W.F., Buggy M., Ellingboe A.R., Young T.M. 2011. Characterising prepreg and non-crimp-fabric composite single lap bonded joints, International Journal of Adhesion \& Adhesives, 31: 679-686.

[10] Khalili S.M.R., Jafarkarimi M.H., Abdollahi M.A. 2009. Creep analysis of fibre reinforced adhesives in single lap joints - Experimental study, International Journal of Adhesion \& Adhesives, 29: 656-661. 
[11] Ariaee S., Tutunchi A., Kianvash A., Entezami A.A. 2014. Modeling and optimization of mechanical behavior of bonded composite-steel single lap joints by response surface methodology, International Journal of Adhesion \& Adhesives, 54: 30-39.

[12] Reis P.N.B., Antunes F.J.V., Ferreira J.A.M. 2005. Influence of superposition length on mechanical resistance of single-lap adhesive joints, Composite Structures, 67: 125-133.

[13] Salih A., Aydin M.D. 2014. 3-D non-linear stress analysis on the adhesively bonded composite joint under bending moment, International Journal of Mechanical Sciences, 81: 149-157.

[14] Daniel I.M., Abot J.L. 2000. Fabrication testing and analysis of composite sandwich beams, Composites Science and Technology, 60: 2455-2463.

[15] Camponeschi E.T. 1990. Compression Response of Thick-Section Composite Materials, ReportDTRC-SME-90/60, David Taylor Research Center, Annapolis, USA.

[16] Sülü İ.Y., Temiz Ş., Aydin M.D. 2015. Layer effects of multi-layered face to face adhesively bonded composite pipes subjected to internal pressure, Academic Journal of Science, 4 (3): 195202.

[17] Sulu I.Y., Temiz S. 2018. Failure and stress analysis of internal pressurized composite pipes joined with sleeves, J. Adhesion Science and Technology, 32 (8): 816-832.

[18] Ozel A., Yazici B., Akpinar S., Aydin M.D., Temiz Ş. 2014. A study on the strength of adhesively bonded joints with different adherends, Composites Part B: Engineering, 62: 167-174.

[19] Temiz S. 2006. Application of bi-adhesive in double-strap joints subjected to bending moment, J. Adhesion Science and Technology, 20: 1547-1560. 